\title{
Low Cross-Polarization Gaussian Tapered Post-Wall Slotline Antenna for Short Pulse Applications
}

\author{
Hongxin Zhao, Yufu Li, and Xiaoxing Yin \\ State Key Laboratory of Millimeter Waves, Southeast University, Nanjing, Jiangsu 210096, China \\ Correspondence should be addressed to Xiaoxing Yin; 101010074@seu.edu.cn
}

Received 4 March 2017; Revised 14 June 2017; Accepted 28 June 2017; Published 31 July 2017

Academic Editor: Ahmed Toaha Mobashsher

Copyright (c) 2017 Hongxin Zhao et al. This is an open access article distributed under the Creative Commons Attribution License, which permits unrestricted use, distribution, and reproduction in any medium, provided the original work is properly cited.

\begin{abstract}
A Gaussian tapered slot antenna based on post-wall structured slotline for improvement of cross-polarization for ultra-wideband applications is proposed and experimentally demonstrated. The antenna is composed of two pairs of Gaussian tapered slotline which have the same structure printed on both sides of the PCB, two metallic via arrays positioned along the slot edges, and two terminal resistors. The metallic via arrays are used to reduce the characteristic impedance of the conventional slotline which form a post-wall slotline and thus can be fed by a coaxial connector directly. More importantly, the balanced symmetrical post-wall structure ensures low cross-polarization levels of the antenna. The Gaussian tapered edges and the terminal resistors diminish reflected signal and thus can enlarge the bandwidth significantly. Good agreements between the simulated and the measured results have been observed. Results show that the proposed antenna exhibits a $-10 \mathrm{~dB}$ impedance bandwidth from $1.5 \mathrm{GHz}$ to $20 \mathrm{GHz}$, a maximum realized gain of $12 \mathrm{dBi}$, and the broadside cross-polarization level is averaged about $-32 \mathrm{~dB}$ in the lower frequency band and $-25 \mathrm{~dB}$ in the higher frequency band with a maximum value of $-22 \mathrm{~dB}$ in the whole working frequency band.
\end{abstract}

\section{Introduction}

With the rapid development of the ultra-wideband and short pulse applications in UWB communication systems and ground penetrating radar (GPR), ultra-wideband antennas, such as TEM horn, log-periodical, helical, and tapered slot antennas (TSA), have been widely studied in recent years. Tapered slot antenna (TSA) is widely used in modern wireless communication systems because of its wideband property, moderate gain, low cost, simple fabrication, planar structure, and good time domain performance [1-5]. TSAs can be categorized into end-fire travelling wave antenna, in which the electromagnetic energy is guided and radiated along the edge of slot [6]. The most concerned in the design of TSAs is the feeding and radiation structure. As the characteristic impedance of the slotline is quite high, a transition from a $50 \mathrm{Ohm}$ coaxial adapter or a microstrip feeding network to the slotline usually shows unsatisfactory performance over the wide bandwidth of the TSA or has complicated structures [7-10]. In order to overcome the bandwidth limitation of feeding structure for the conventional TSAs, antipodal TSA and its various forms with fins printed on opposite sides of the substrate were presented by many researchers in the past. Compared to the traditional TSAs, antipodal TSAs can be fed easily with microstrip lines and SMA connectors, but it is not suitable in large array applications and its cross-polarization levels is quite high [11-17]. For the radiation structure, a plethora of tapered profiles, such as the common exponential profile and linear profile, have been reported to design TSAs. However, the sudden discontinuity at the antenna terminal still produces large reflection, which lays severe constraints on the antenna bandwidth $[18,19]$.

In this letter, a novel ultra-wideband Gaussian tapered post-wall slotline antenna is proposed. The post-wall slotline $[20,21]$ is featured by low characteristic impedance and it can be fed by a coaxial connector directly, which is beneficial for diminishing the reflection signal. The smooth Gaussian tapered slot edge and the terminal resistors are favorable for enlarging the bandwidth. Due to its bilateral and symmetrical structure, loading resistor can be easily mounted and crosspolarization level can be highly suppressed compared to the design in [17]. It is demonstrated by the simulated results and 


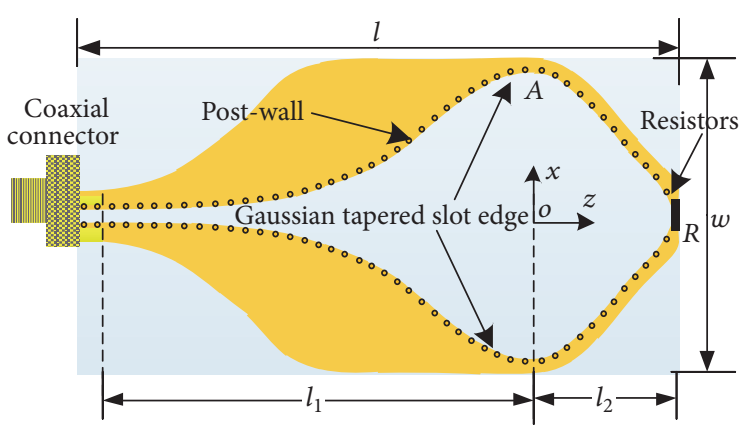

FIGURE 1: Configuration of proposed Gaussian tapered post-wall slotline antenna.

the measured results that the proposed antenna is featured by broad bandwidth, low cross-polarization levels, moderate gain, and suitability for short pulse applications.

\section{Antenna Geometry and Design}

The geometry of the proposed Gaussian tapered post-wall slotline antenna is shown in Figure 1. The antenna is printed on a substrate of Rogers 4003C, with size of $l \times w$, a thickness of $0.813 \mathrm{~mm}$, relative permittivity of 3.55 , and loss tangent of 0.0027 . The post-wall slotline of the antenna is composed of a bilateral slotline and two arrays of metallic vias which are aligned along the slot edges. The fins of the bilateral slotline on top and bottom surface of the substrate are with the same structure and are connected by the metallic vias. The vias in each array are placed uniformly and compactly to form the conductive post-wall. Therefore, the capacitance per unit length of the post-wall slotline is higher than that of a common slotline, which effectuates low characteristic impedance and enables the direct feeding by a coaxial connector.

The edges of the post-wall form a rhombus-like shape and taper in accordance with a Gaussian function. Denoting the turn of the rhombus as point $A$ and positioning the original point of the coordinate system under point $A$, the Gaussian tapered profile can be expressed as follows:

$$
x(z)= \begin{cases}m \cdot \exp \left(-4 \pi\left(\frac{z}{\tau_{1}}\right)^{2}\right), & \text { for }-l_{1} \leq z \leq 0 \\ m \cdot \exp \left(-4 \pi\left(\frac{z}{\tau_{2}}\right)^{2}\right), & \text { for } 0 \leq z \leq l_{2},\end{cases}
$$

where $m$ determines the maximum of the Gaussian function, $\tau_{1}$ and $\tau_{2}$ indicate the width of the Gaussian profiles, and $l_{1}$ and $l_{2}$ denote the length of the diverging region from the feeding point to point $A$ and the length of the converging region from point $A$ to the end of the slotline, respectively. The derivative of the Gaussian function at point $A$ is designed to be zero, which indicates a smooth transition from the diverging region to the converging region. Two terminal resistors, with value of $R$, are loaded to connect the two converging fins on top and bottom surfaces of the substrate, respectively. The smooth Gaussian tapered profile and the terminating resistors corporately enlarge the bandwidth.

The proposed Gaussian tapered post-wall slotline antenna has been simulated and optimized using CST MWS. The value of the loaded resistor and key parameters for the Gaussian tapered profile influence the reflected signal a lot. Figure 2 shows, respectively, $\left|S_{11}\right|$ with different values of $R, \tau_{1}$.

Figure 3 shows, respectively, the photograph of the top side and bottom side of the proposed antenna. The final results with the optimized parameters for the proposed antenna are listed below.

\section{Simulated and Experimental Results}

The proposed Gaussian tapered post-wall slotline antenna has been measured using an Agilent vector network analyzer N5230A in anechoic chamber. A Gaussian pulse with a $-10 \mathrm{~dB}$ impedance bandwidth from 0 to $20 \mathrm{GHz}$ is used to excite the proposed antenna. The simulated and measured reflection coefficients of the proposed antenna are shown in Figure 4(a).

Time domain characterization is an attractive description method for short pulse antenna performance. To illustrate the short pulse performance of the proposed antenna, port signals in time domain derived from the measured scattering parameters are depicted in Figure 4(b) along with simulated results. The Gaussian pulse with a $-10 \mathrm{~dB}$ bandwidth from $\mathrm{DC}$ to $20 \mathrm{GHz}$ is utilized as the stimulus signal and is expressed as

$$
G(t)=\exp \left(-\frac{4 \pi\left(t-t_{0}\right)^{2}}{\tau^{2}}\right),
$$

where $t_{0}$ equals $0.08885 \mathrm{~ns}$ and $\tau$ is $0.086 \mathrm{~ns}$. The spectrum of the Gaussian pulse is denoted by $G(f)$. The Gaussian pulse shown in (2) is used to calculate the pulse waveforms along with the measured scattering parameters. The measured reflected pulse signal $b_{11}(t)$ is derived as follows:

$$
b_{11}(t)=\operatorname{IFFT}\left\{\frac{E}{O}\left[G(f) \cdot S_{11-m}(f)\right]\right\},
$$

where $S_{11-m}(f)$ represents the measured scattering parameters of the fabricated antenna and $E / O$ represents the even symmetry operation of the magnitude spectrum and the odd symmetry operation of the phase spectrum.

A good agreement has been observed between the simulated and the measured results. Both of the results show that $\left|S_{11}\right|$ is lower than $-10 \mathrm{~dB}$ from about $1.5 \mathrm{GHz}$ to $20 \mathrm{GHz}$, which indicates the ultra-wideband property of the proposed antenna. Figure 4(b) shows the input signal and the reflected signal observed at the feed port in the simulation. It is seen that the peak value of the reflected signal is lower than 0.1 and the trailing pulse after $1.25 \mathrm{~ns}$ is quite small, which also indicates the good impedance matching of the antenna.

Simulated efficiency of the presented antenna at different frequencies is shown in Figure 5; it can be concluded that the total efficiency is more than $70 \%$ in the whole working frequency band. Figure 6(a) depicts the simulated and 

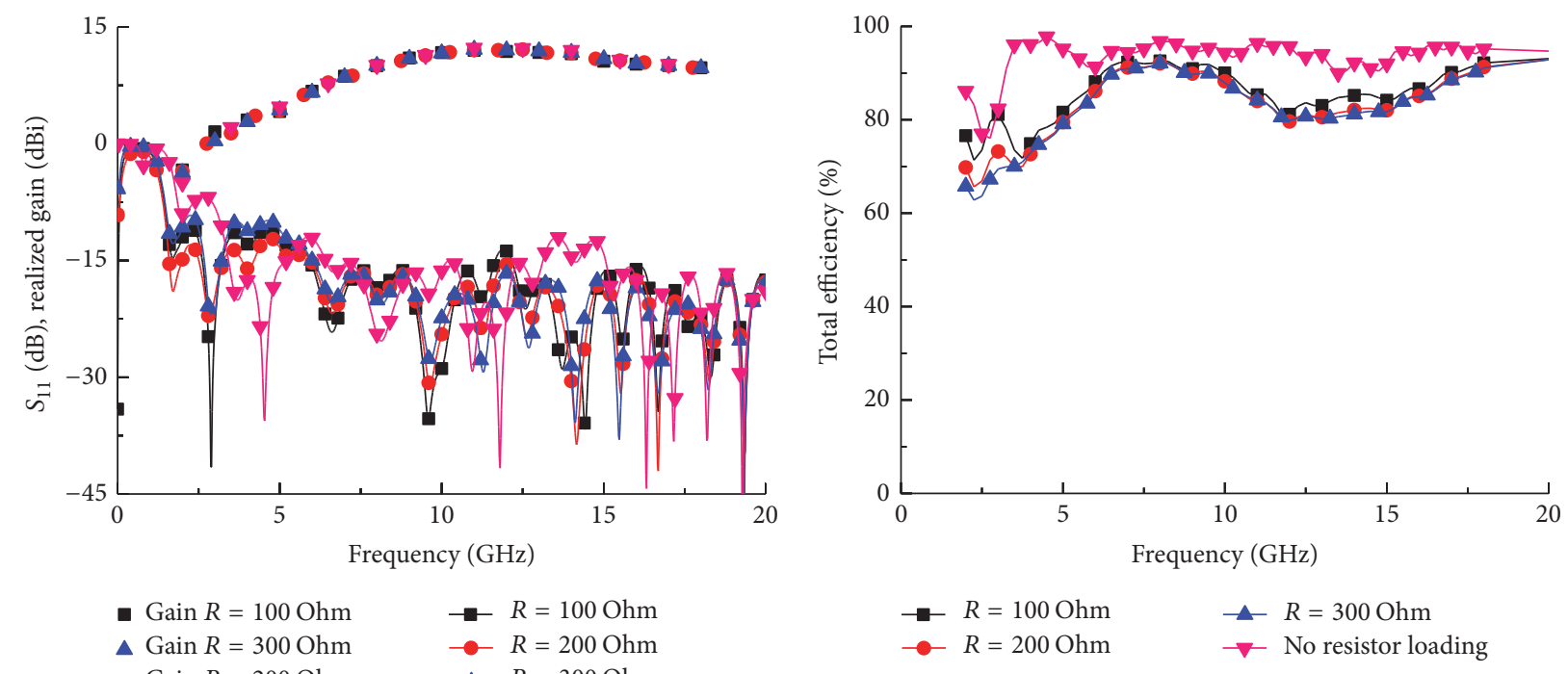

- Gain $R=100 \mathrm{Ohm}$

$\rightarrow-R=100 \mathrm{Ohm}$

$\rightarrow R=200 \mathrm{Ohm}$

$\longrightarrow R=200 \mathrm{Ohm}$

$\rightarrow$ No resistor loading

- Gain $R=200 \mathrm{Ohm}$

- $R=300 \mathrm{Ohm}$

$\nabla$ Gain no resistor loading $\quad \rightarrow-$ No resistor loading

(a)

(b)

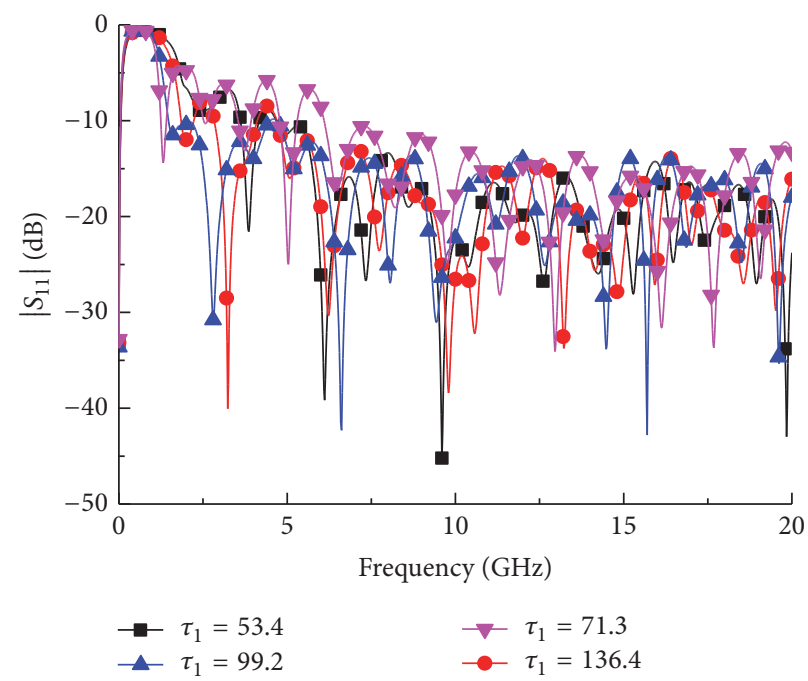

(c)

Figure 2: Effect of $R$ and $\tau_{1}$. (a) Simulated $S_{11}$ and realized gain with different value of $R$, (b) simulated total efficiency with different value of $R$, and (c) simulated $S_{11}$ with different value of $\tau_{1}$.

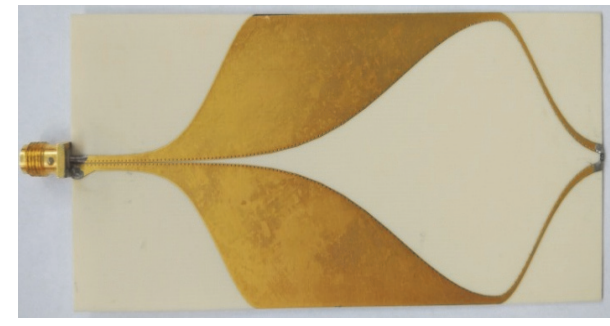

(a)

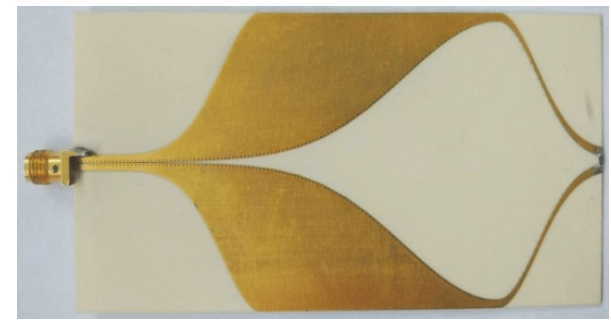

(b)

Figure 3: Photos of the proposed antenna. (a) Top side and (b) bottom side. $l=112 \mathrm{~mm}, w=53.4 \mathrm{~mm}, l_{1}=84 \mathrm{~mm}, l_{2}=23 \mathrm{~mm}, R=$ $200 \mathrm{Ohm}, \tau_{1}=99.2$, and $\tau_{2}=42.4$. 


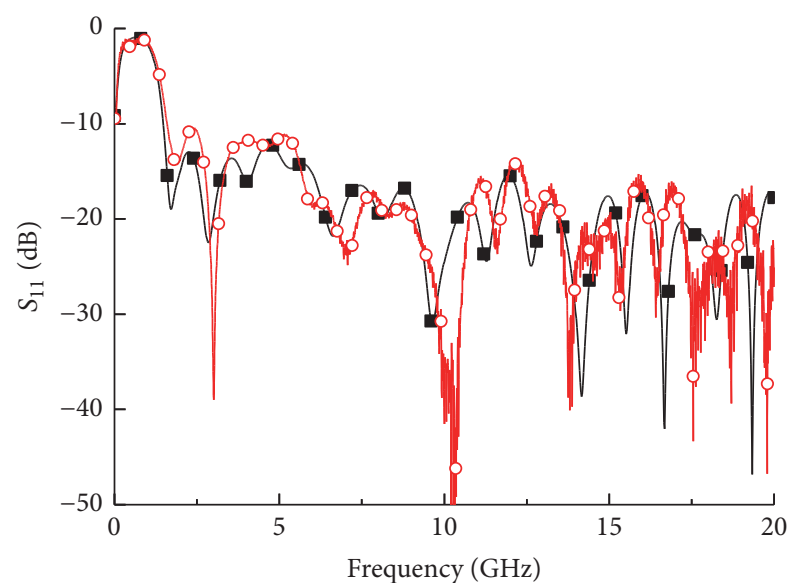

$\rightarrow$ Simulated $-S_{11}$ $\multimap$ Measured- $S_{11}$

(a)

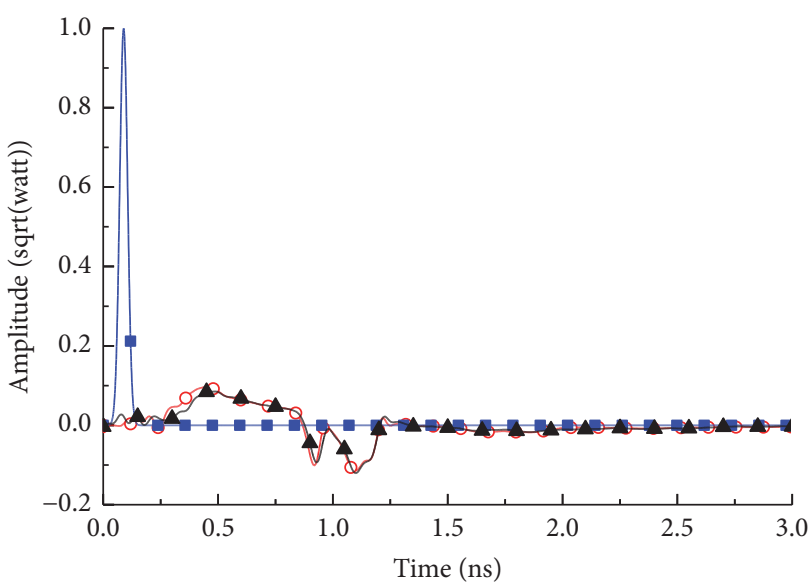

$\longrightarrow$ Simulated-input signal, $G(t)$

- - Simulated-reflected signal, $b_{11}(t)$

^- Measured-reflected signal, $b_{11}(t)$

(b)

FIGURE 4: Simulated and measured port parameters. (a) Simulated and measured reflection coefficients and (b) input and reflected signals.

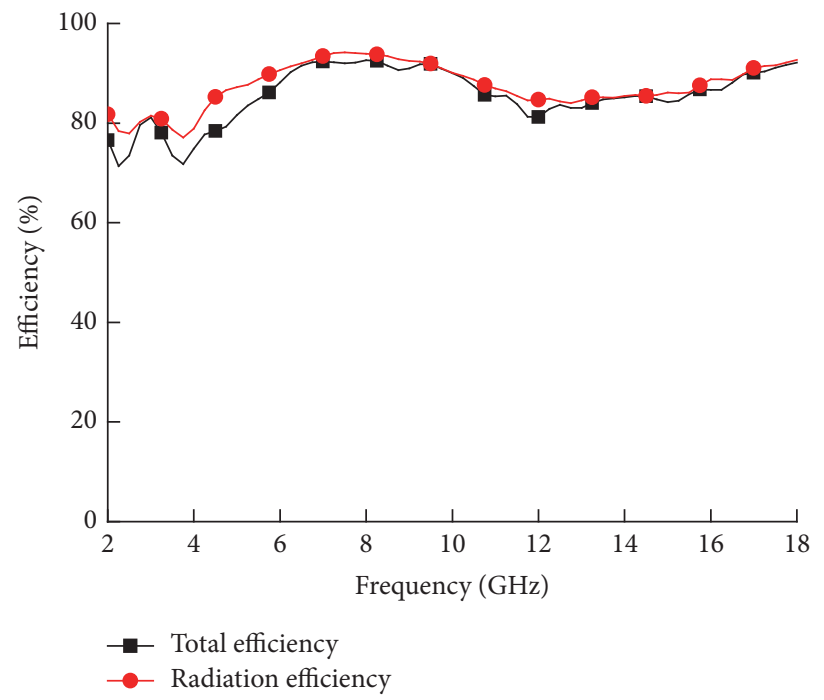

FIgURE 5: Simulated efficiency.

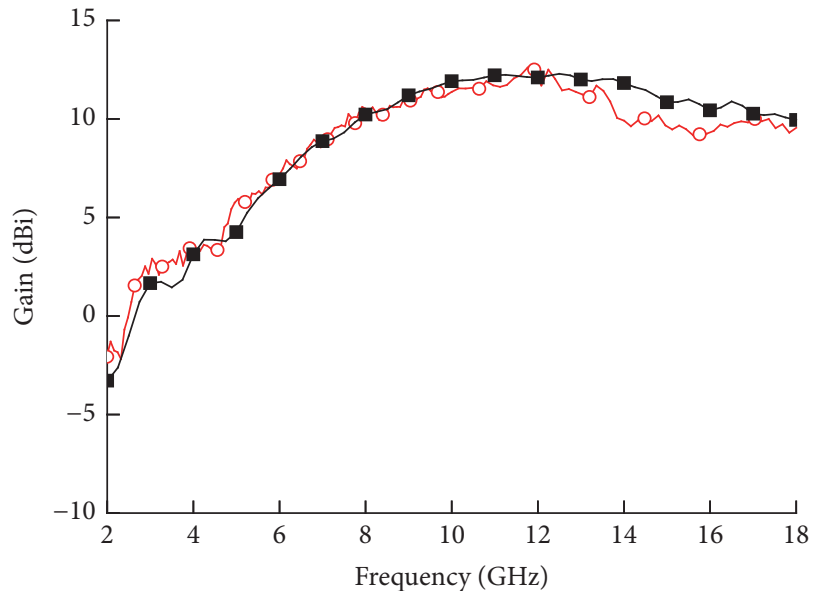

- Simulated realized gain - - Measured realized gain

(a)

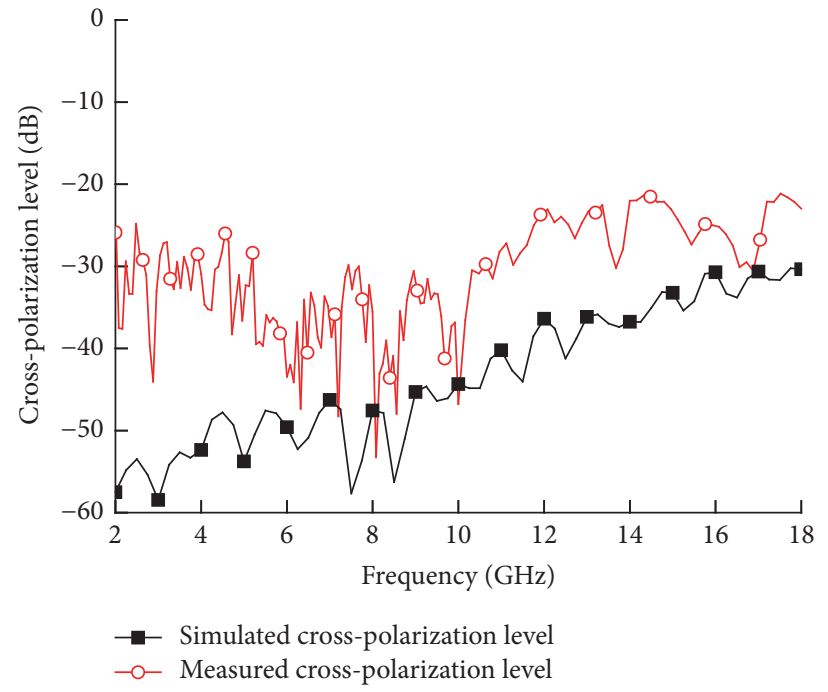

(b)

FIGURE 6: Gain and cross-polarization level. (a) Realized gain in main radiation direction and (b) cross-polarization levels in main radiation direction. 


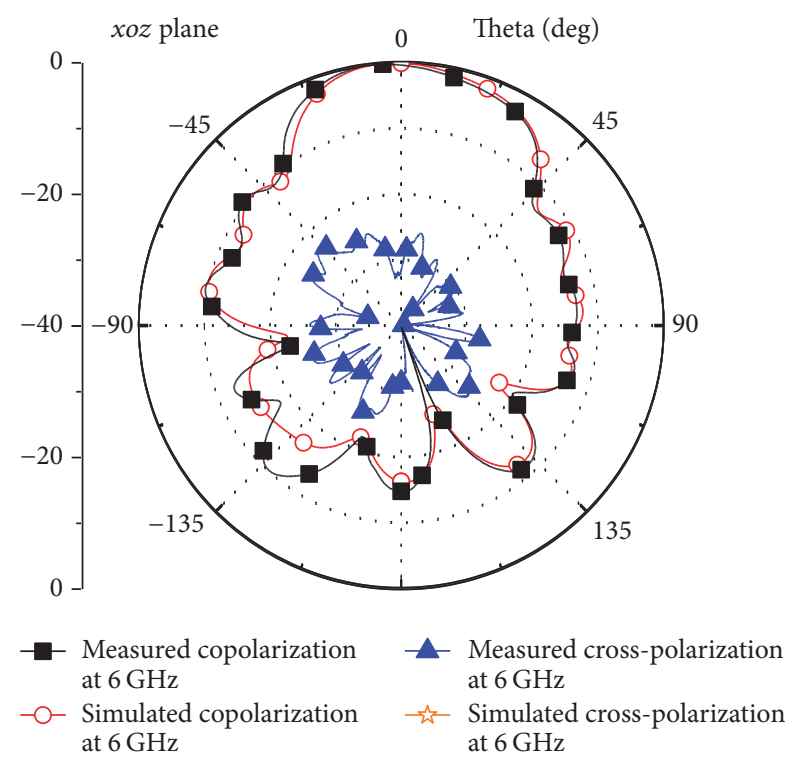

(a)

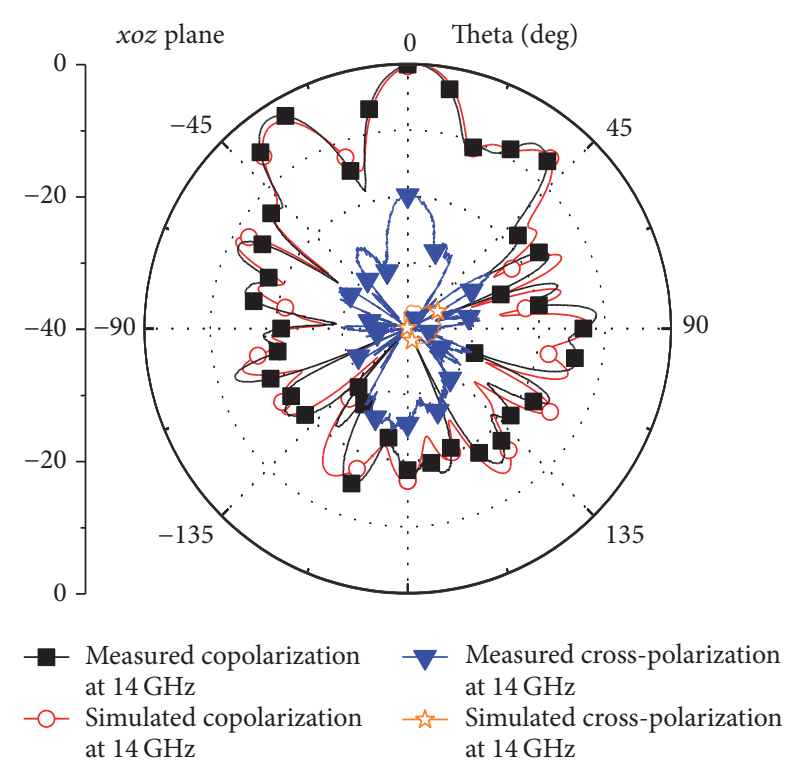

(c)

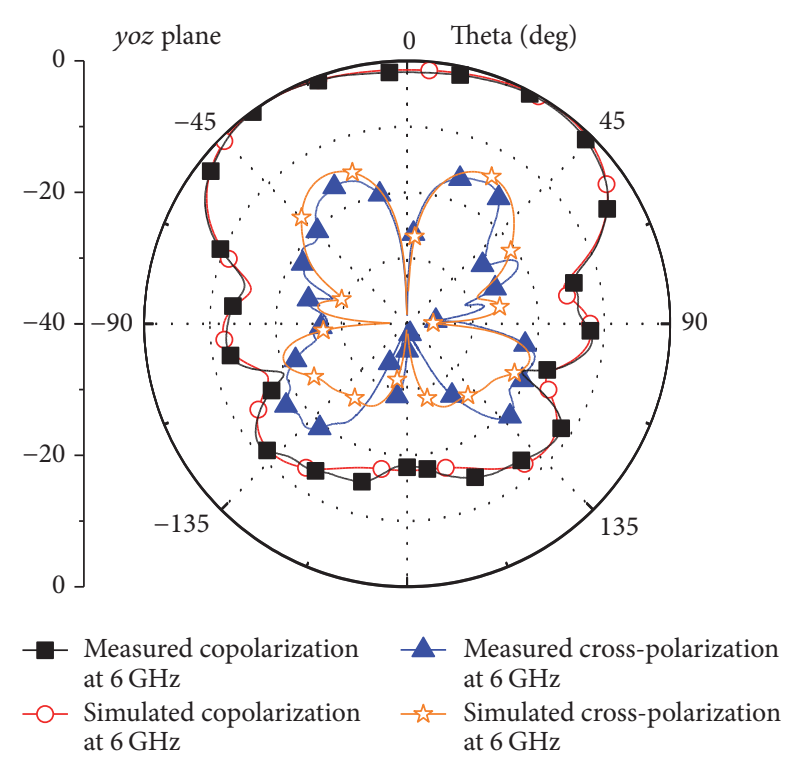

(b)
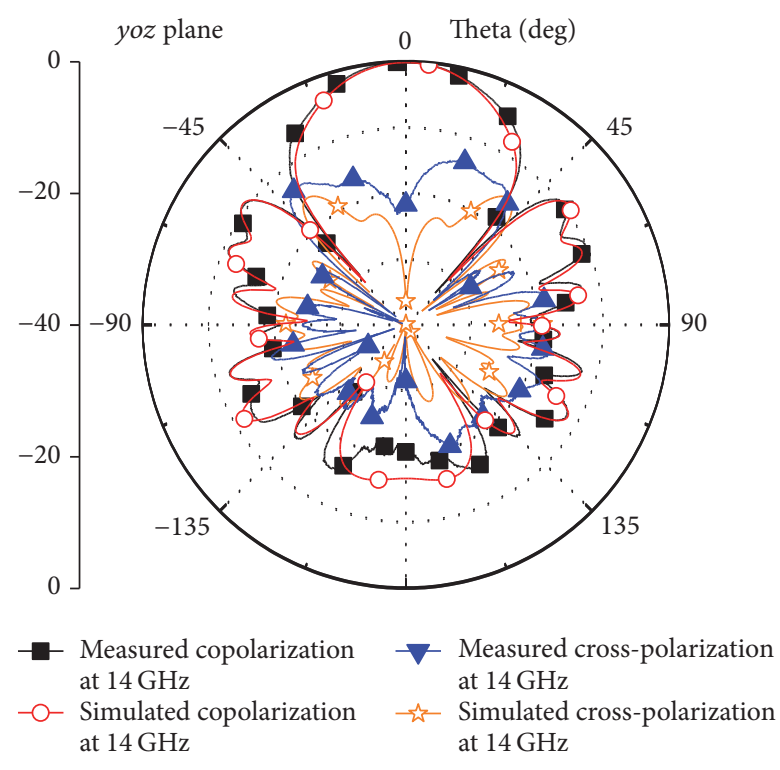

(d)

Figure 7: Simulated and measured radiation patterns. (a) Patterns in E-plane at $6 \mathrm{GHz}$, (b) patterns in $H$-plane at $6 \mathrm{GHz}$, (c) patterns in $E$-plane at $14 \mathrm{GHz}$, and (d) patterns in $\mathrm{H}$-plane at $14 \mathrm{GHz}$.

measured realized gain in the main radiation direction of the proposed antenna. It can be found that the measured gain agrees quite well with the simulated results in most of the working frequency band, and the gain is larger than about $3 \mathrm{dBi}$ from $4 \mathrm{GHz}$ with a peak value of $12 \mathrm{dBi}$ at $12.5 \mathrm{GHz}$. Figure $6(\mathrm{~b})$ gives the comparison between the simulated and the measured cross-polarization levels in the main radiation direction of the proposed antenna. The simulated result shows that the cross-polarization level of the proposed antenna increases from lower frequency band to higher frequency band and is lower than $-30 \mathrm{~dB}$ across the concerned frequency band. The measured result is larger than the simulated result, but it can be observed that the measured cross-polarization level is lower than $-22 \mathrm{~dB}$ across the whole frequency band.

The simulated and measured radiation patterns in the $E$ plane and $H$-plane are shown in Figure 7 . Considering the broad bandwidth of the proposed antenna, the patterns at $6 \mathrm{GHz}$ and $14 \mathrm{GHz}$ are given to characterize the radiation performance. As shown in Figure 7, the simulated and measured radiation patterns in copolarization agree quite well. The proposed antenna has directional radiation patterns and the main direction is along the $z$-axis. The measured crosspolarization levels at $6 \mathrm{GHz}$ and at $14 \mathrm{GHz}$ are both lower 


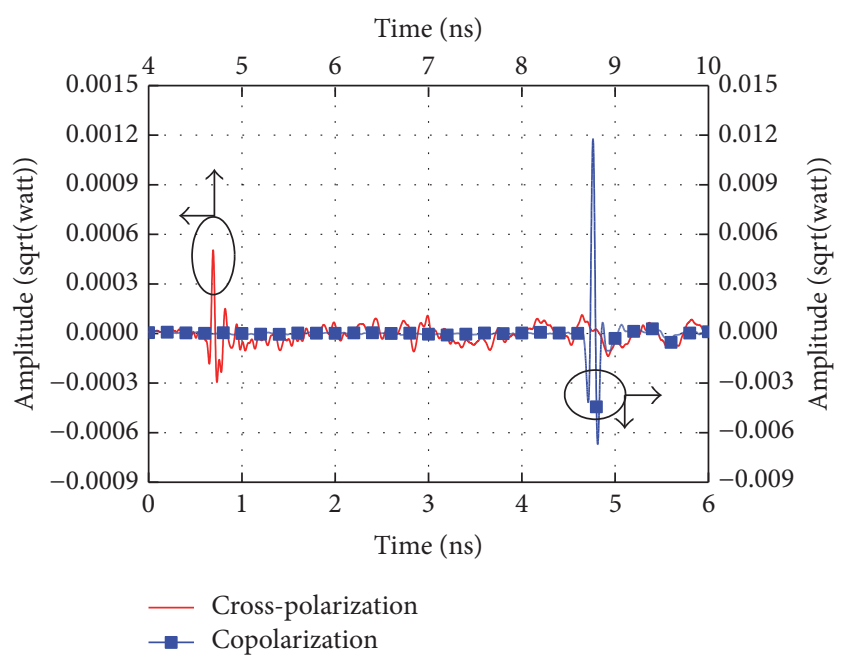

FIGURE 8: The transmission of short pulse signals between two antennas.

than $-20 \mathrm{~dB}$ in E-plane and are lower than about $-15 \mathrm{~dB}$ in $H$-plane.

To obtain the transmission performance, two identical proposed antennas were placed 1.3 meters apart along the main radiation direction in the anechoic chamber and the transmission coefficients $S_{21}(f)$ under the copolarization and the cross-polarization conditions were measured by using vector network analyzer. Figure 8 gives the measured transmission signals $b_{21}(f)$ of the two identical antennas positioned in copolarization and in cross-polarization, respectively.

\section{Conclusion}

An ultra-wideband rhombus-like Gaussian tapered postwall slotline antenna is proposed. The rhombus-like postwall slotline presents low characteristic impedance and is fed by a coaxial connector directly and enables low crosspolarization levels of the antenna. The Gaussian tapered edges and the terminal resistors diminish reflected signal and enlarge the bandwidth significantly. Good agreements between the simulated and the measured results have been observed. Results show that the proposed antenna exhibits $-10 \mathrm{~dB}$ impedance bandwidth from $1.5 \mathrm{GHz}$ to $20 \mathrm{GHz}$, a maximum realized gain of $12 \mathrm{dBi}$, and the broadside crosspolarization levels lower than $-22 \mathrm{~dB}$ in the whole working frequency band.

\section{Conflicts of Interest}

The authors declare that they have no conflicts of interest.

\section{Acknowledgments}

This work was supported in part by National Natural Science Foundation of China under Grant 61427801 and in part by National Natural Science Foundation of China under
Grant U1536123. The authors would like to express their appreciation to State Key Laboratory of Millimeter Waves.

\section{References}

[1] H. G. Schantz, "A brief history of UWB antennas," IEEE Aerospace and Electronic Systems Magazine, vol. 19, no. 4, pp. 22-26, 2004.

[2] K. S. Yngvesson, T. L. Korzeniowski, Y.-S. Kim, E. L. Kollberg, and J. F. Johansson, "Tapered slot antenna-new integrated element for millimeter-wave applications," IEEE Transactions on Microwave Theory and Techniques, vol. 37, no. 2, pp. 365-374, 1989.

[3] J. Shao, G. Fang, Y. Ji, K. Tan, and H. Yin, "A novel compact tapered-slot antenna for GPR applications," IEEE Antennas and Wireless Propagation Letters, vol. 12, pp. 972-975, 2013.

[4] Y. Yao, W. Chen, B. Huang, Z. Feng, and Z. Zhang, "Analysis and Design of Tapered Slot Antenna for Ultra-Wideband Applications," Tsinghua Science and Technology, vol. 14, no. 1, pp. 1-6, 2009.

[5] F. Zhang, G.-Y. Fang, Y.-C. Ji, H.-J. Ju, and J.-J. Shao, "A novel compact double exponentially tapered slot antenna (DETSA) for GPR applications," IEEE Antennas and Wireless Propagation Letters, vol. 10, pp. 195-198, 2011.

[6] K. S. Yngvesson, D. H. Schaubert, T. L. Korzeniowski, E. L. Kollberg, T. Thungren, and J. F. Johansson, "Endfire tapered slot antennas on dielectric substrates," IEEE Transactions on Antennas and Propagation, vol. 33, no. 12, pp. 1392-1400, 1985.

[7] K. Hettak, G. Y. Delisle, S. Tardif, G. A. Morin, and M. G. Stubbs, "A novel wideband Chebychev tapered slot antenna using broadband CPW to slotline transition," in Proceedings of the 2008 IEEE International Symposium on Antennas and Propagation and USNC/URSI National Radio Science Meeting, APSURSI, San Diego, Calif, USA, July 2008.

[8] P. Knott and A. Bell, "Coaxially-fed tapered slot antenna," Electronics Letters, vol. 37, no. 18, pp. 1103-1104, 2001.

[9] I. Mohamed and A. Sebak, "Linearly tapered slot antenna array with SIW feed network for $60 \mathrm{GHz}$ applications," in Proceedings of the 17th International Symposium on Antenna Technology and Applied Electromagnetics, ANTEM 2016, Montreal, Canada, July 2016.

[10] T.-G. Lim, H.-N. Ang, I. D. Robertson, and B. L. Weiss, "Kaband CPW-to-slotline transition in photoimageable thick film technology for tapered slot antenna applications," Microwave and Optical Technology Letters, vol. 48, no. 10, pp. 2032-2034, 2006.

[11] Z. Zhou, S. Yang, and Z. Nie, "A novel broad-band printed dipole antenna with low cross-polarization," IEEE Transactions on Antennas and Propagation, vol. 55, no. 11, pp. 3091-3093, 2007.

[12] J. D. S. Langley, P. S. Hall, and P. N. Newham, "Novel ultrawidebandwidth Vivaldi antenna with low crosspolarisation," Electronics Letters, vol. 29, no. 23, pp. 2004-2005, 1993.

[13] H. Oraizi and S. Jam, "Optimum design of tapered slot antenna profile," IEEE Transactions on Antennas and Propagation, vol. 51, no. 8, pp. 1987-1995, 2003.

[14] H. Li, L. Chen, J. Qiu, and C. Yang, "A compact antipodal vivaldi antenna with improved radiation performance," in Proceedings of the International Symposium on Antennas and Propagation (ISAP '16), pp. 380-381, Okinawa, Japan, 2016. 
[15] R. Natarajan, M. Kanagasabai, and M. G. N. Alsath, "Dual mode antipodal Vivaldi antenna," IET Microwaves, Antennas and Propagation, vol. 10, no. 15, pp. 1643-1647, 2016.

[16] J. D. S. Langley, P. S. Hall, and P. Newham, "Balanced antipodal Vivaldi antenna for wide bandwidth phased arrays," IEE Proceedings - Microwaves, Antennas and Propagation, vol. 143, no. 2, pp. 97-102, 1996.

[17] M. Yang, X. Yin, Y. Li, and L. Liu, "Ultra-Wideband Planar Gaussian Tapered Rhombic Antenna for Short Pulse Applications," IEEE Antennas and Wireless Propagation Letters, vol. 15, pp. 48-51, 2016.

[18] D. M. Elsheakh and E. A. Abdallah, "Ultrawideband Vivaldi antenna for DVB-T, WLAN, and WiMAX applications," International Journal of Antennas and Propagation, vol. 2014, Article ID 761634, 7 pages, 2014.

[19] Z. Li, X. Kang, J. Su, Q. Guo, Y. L. Yang, and J. Wang, "A Wideband End-Fire Conformal Vivaldi Antenna Array Mounted on a Dielectric Cone," International Journal of Antennas and Propagation, vol. 2016, Article ID 9812642, 2016.

[20] H. Zhao and M. Yang, "Ultra-wideband short-pulse power divider based on coplanar waveguide and slotline structure," Electronics Letters, vol. 51, no. 24, pp. 2023-2024, 2015.

[21] S. Li, X. Yin, H. Zhao, and H. Qi, "Postwall slotline and its application in design of short-pulse tapered slot antennas," Institute of Electrical and Electronics Engineers. Transactions on Antennas and Propagation, vol. 63, no. 8, pp. 3400-3409, 2015. 


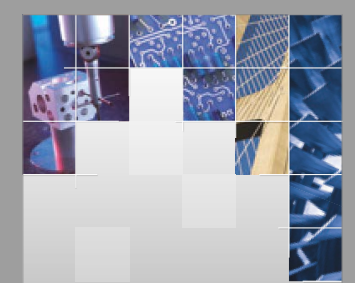

\section{Enfincering}
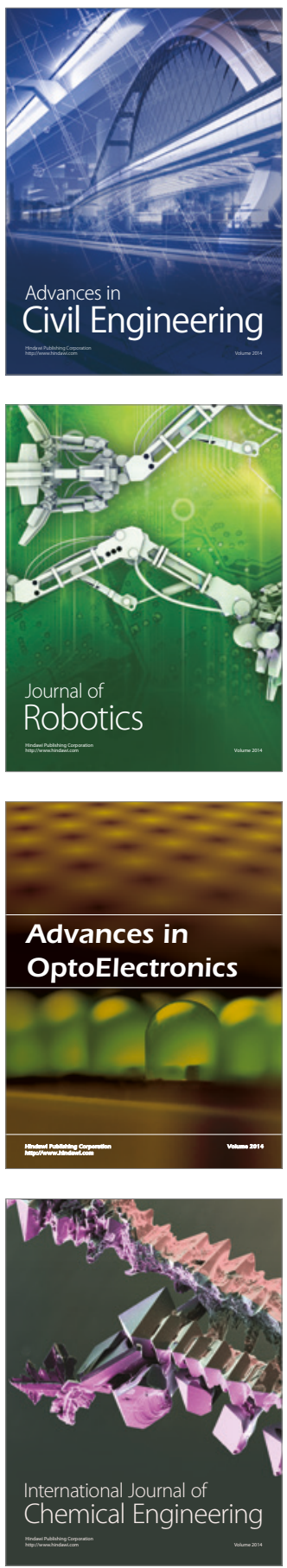

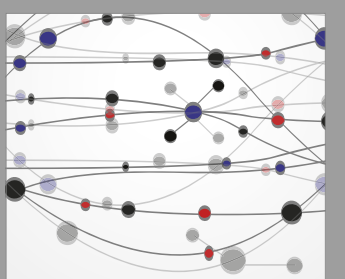

The Scientific World Journal
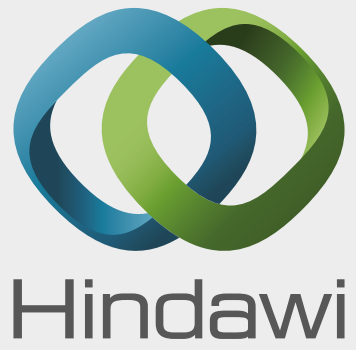

Submit your manuscripts at

https://www.hindawi.com
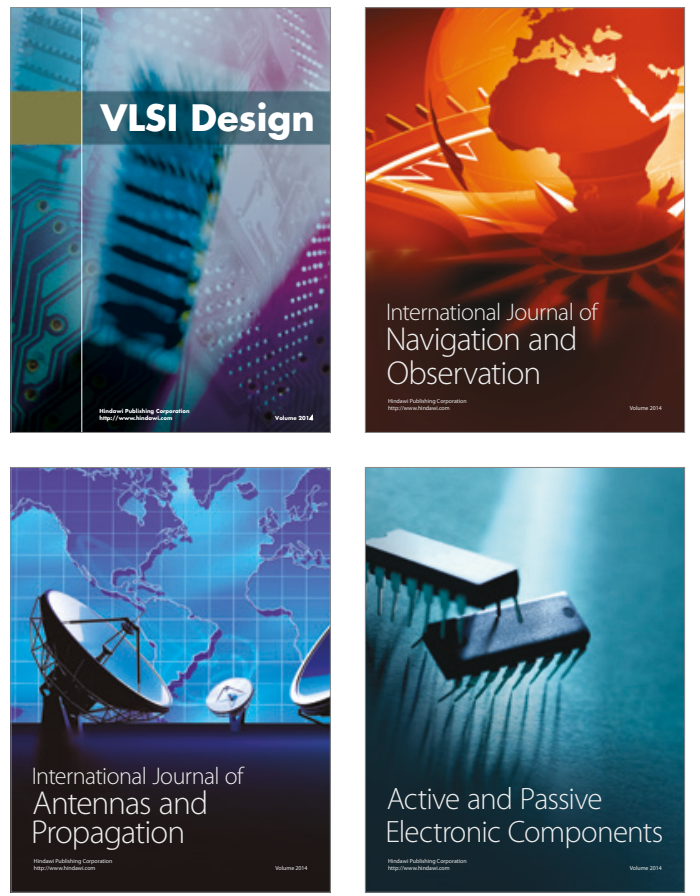

\section{Rotating}

Machinery

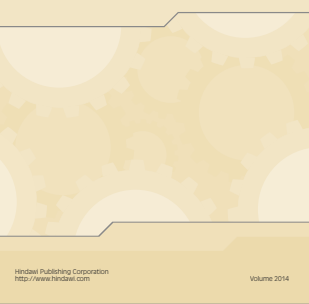

Journal of

Sensors

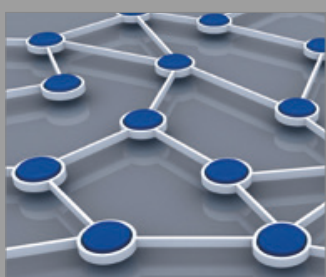

International Journal of

Distributed

Sensor Networks

Journal of

Control Science

and Engineering
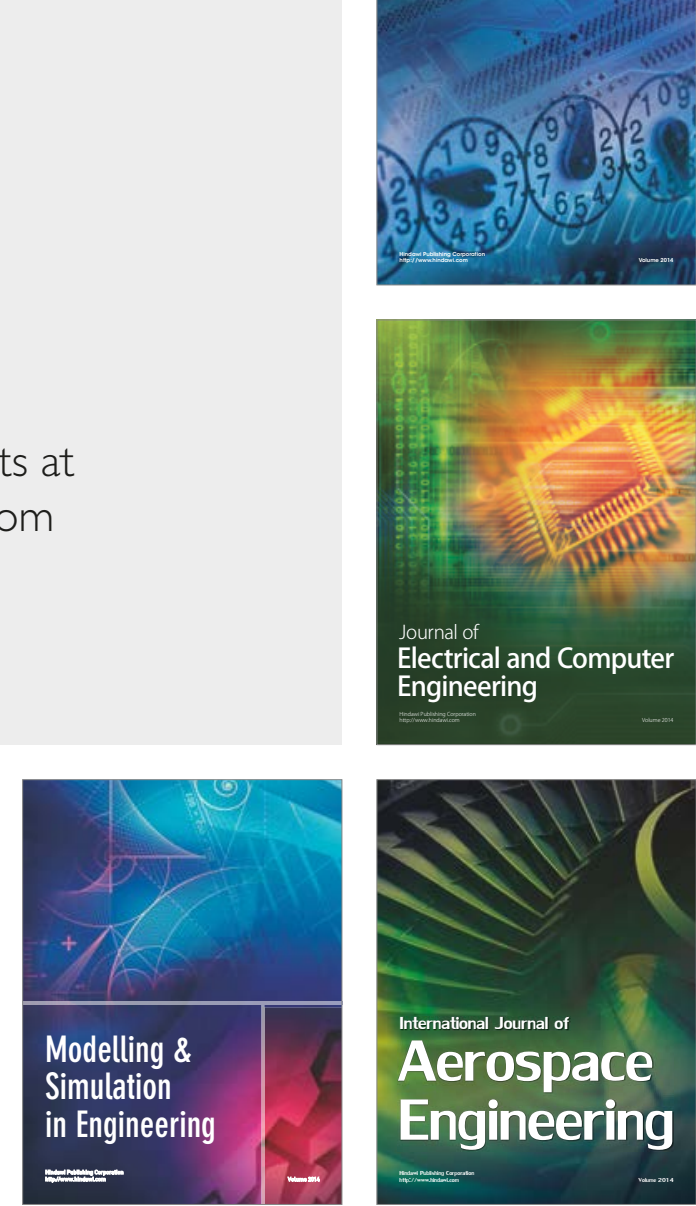
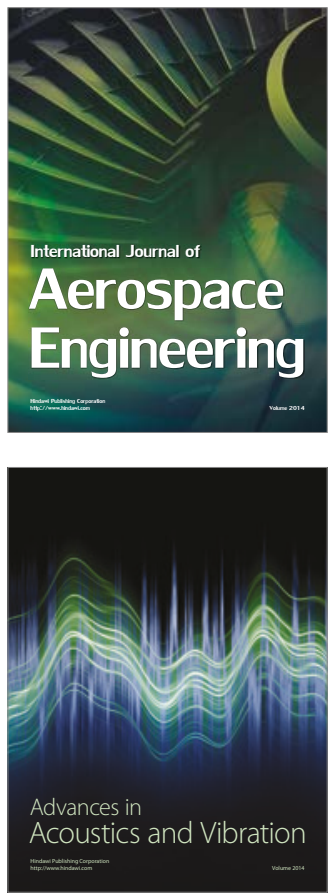